ZOOLOGIA 31 (6): 644-644, December, 2014

http://dx.doi.org/10.1590/S1984-46702014000600011

\title{
Errata for ZOOLOGIA volumes 29(2) and 31(2)
}

Volume 29(2), page 150:

The correct version for Figures 19-20 is presented below:
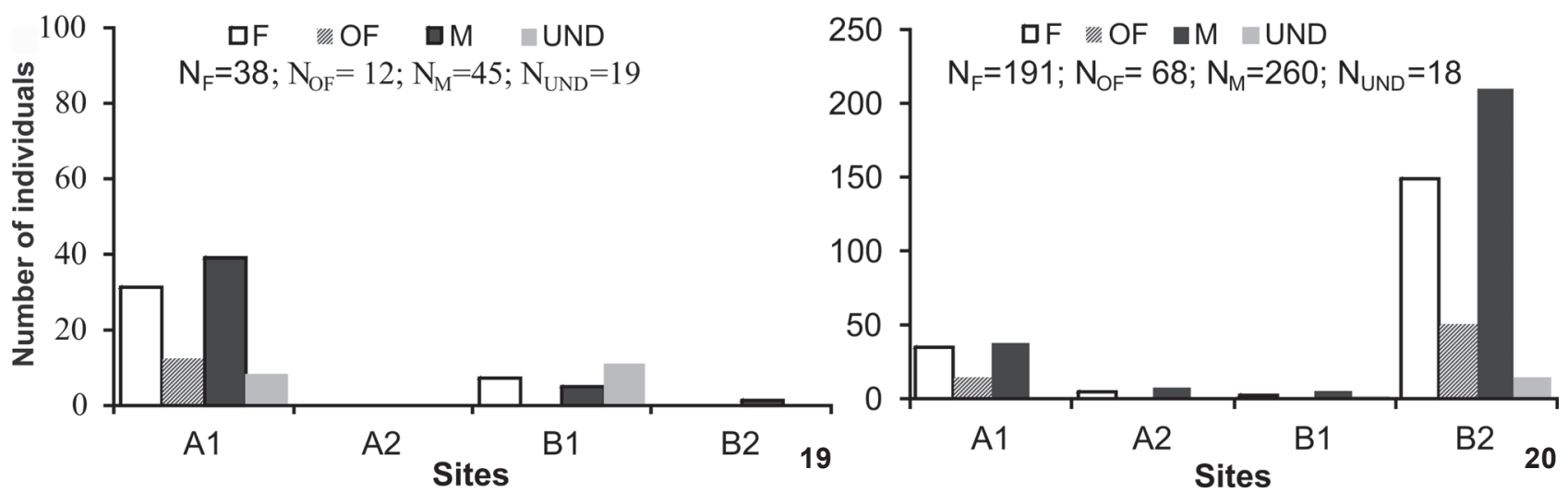

Figures 19-20. Number of L. siriboia and U. vasquezi individuals sorted by sex, according to species and sampling site from August 2006 to July 2007 in the Marapanim estuary, Pará, Brazil. (F) Female, (OF) ovigerous female, (M) male, (UND) undetermined sex.

\section{Volume 31(2), page 201:}

The correct version for Figures 23 and 24 is presented below:
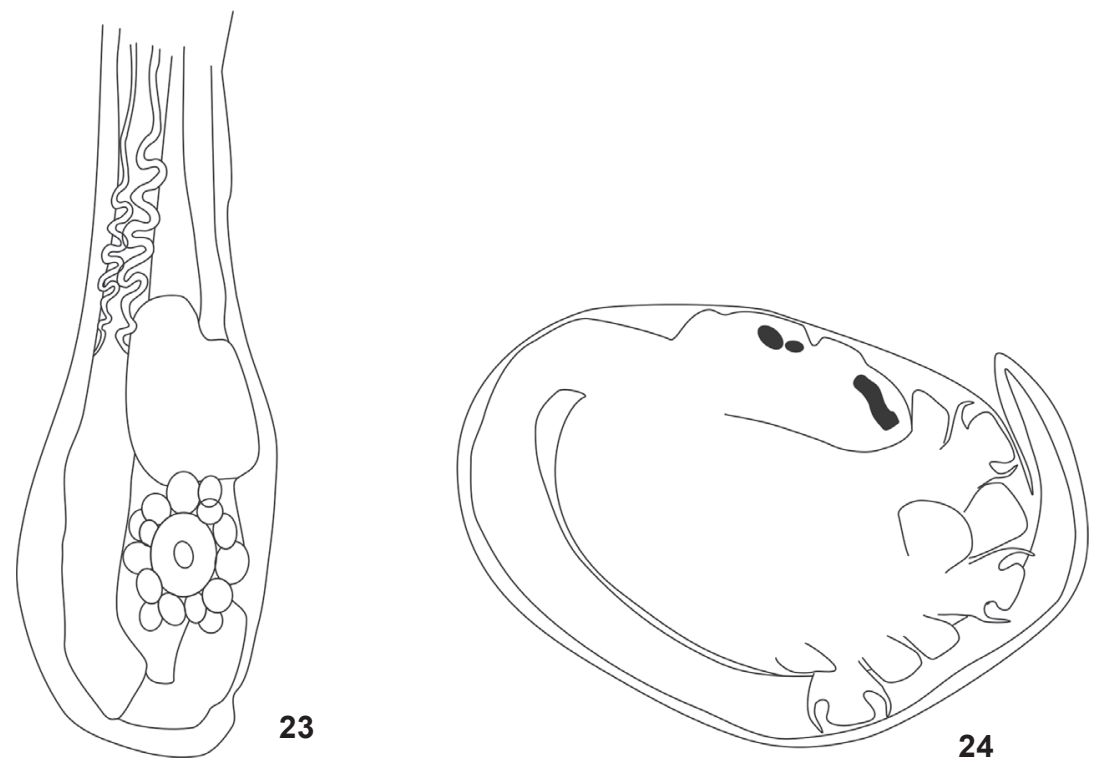

All changes are already incorporated in the online version of these articles available at http://www.scielo.br/zool

2014 Sociedade Brasileira de Zoologia | www.sbzoologia.org.br | www.scielo.br/zool

All content of the journal, except where identified, is licensed under a Creative Commons attribution-type BY-NC. 